\title{
Association of the interleukin-28B gene polymorphism with development of hepatitis virus-related hepatocellular carcinoma and liver cirrhosis: a meta-analysis
}

\author{
G.J. Suo and Z.X. Zhao \\ Department of Digestive Surgery, East Hospital, \\ Tongji University School of Medicine, Shanghai, China. \\ Corresponding author: G.J. Suo \\ E-mail: guangjunsuo@hotmail.com \\ Genet. Mol. Res. 12 (3): 3708-3717 (2013) \\ Received January 16, 2013 \\ Accepted August 28, 2013 \\ Published September 19, 2013 \\ DOI http://dx.doi.org/10.4238/2013.September.19.1
}

\begin{abstract}
We examined the association of the interleukin-28B (IL-28B) gene rs12979860 T/C polymorphism with development of hepatitis virus-related hepatocellular carcinoma (HCC) and liver cirrhosis (LC). Two investigators independently searched the PubMed, Elsevier, EMBASE, Web of Science, Wiley Online Library, and Chinese National Knowledge Infrastructure data bases. Pooled odds ratios (ORs) and $95 \%$ confidence intervals $(95 \% \mathrm{CIs})$ for rs 12979860 and HCC/LC were calculated in a fixed-effect model (the Mantel-Haenszel method) and a random-effect model (the DerSimonian and Laird method) when appropriate. This meta-analysis included 7 eligible studies, with 1152 HCC and/or LC cases and 1326 controls. Overall, the rs $12979860 \mathrm{~T} / \mathrm{C}$ polymorphism was significantly associated with risk of hepatitis virusrelated $\mathrm{HCC}$ and $\mathrm{LC}$ development (TT vs $\mathrm{CC}+\mathrm{CT}$, pooled $\mathrm{OR}=1.597$, $95 \% \mathrm{CI}=1.254-2.036)$. When they were grouped by type of hepatitis virus, similar results were found for hepatitis $\mathrm{C}$ virus-related groups (TT vs $\mathrm{CC}+\mathrm{CT}$, pooled $\mathrm{OR}=1.732,95 \% \mathrm{CI}=1.343-2.235$, $\mathrm{P}$ value $<0.0001)$. In the overall analysis, the IL-28B rs12979860 T/C polymorphism was
\end{abstract}


identified as a genetic risk factor for hepatitis virus-related HCC and LC development. A significant increase in the frequency of the T/T genotype was detected from chronic hepatitis to HCC and LC.

Key words: Hepatocellular carcinoma; Liver cirrhosis; rs12979860; Interleukin-28B; Gene polymorphism; Meta-analysis

\section{INTRODUCTION}

The natural history of hepatitis virus infection varies from spontaneous recovery post-infection, chronic asymptomatic carrier to decompensated cirrhosis and hepatocellular carcinoma (Villeneuve, 2005; Leone and Rizzetto, 2005). Approximately 30\% of individuals clear the infection naturally, whereas the remaining 70\% develop chronic disease (Lavanchy, 2004; Nash et al., 2010; Morgan, 2011). During chronic hepatitis C, progressive fibrosis deposition occurs and this deposition ends in cirrhosis in $20-30 \%$ of chronic hepatitis $\mathrm{C}$ virus (HCV) carriers and $2.5 \%$ of HCV-infected individuals develop hepatocellular carcinoma (HCC) later in life (Poynard et al., 1997; Bowen and Walker, 2005). Progression to cirrhosis occurs at an annual rate of 2-5\% in HBeAg-positive patients and the risk of HCC in patients with chronic hepatitis B, and cirrhosis is over $2 \%$ per year, with a cumulative 5 -year incidence of 15-20\% (Fattovich et al., 1995; Ikeda et al., 1998).

During the last 2 decades, interferon-based therapeutic regimens have been used to treat chronic viral hepatitis caused by hepatitis B virus (HBV) and HCV, with the aim to alter the natural history of these diseases (Bruno and Facciotto, 2008). In 2009, the rs12979860 C/T polymorphism, located $3 \mathrm{~kb}$ upstream of the interleukin-28B (IL-28B) gene, is shown to be strongly associated with more than a 2-fold difference in response to $\mathrm{HCV}$ drug treatment, both in patients of European ancestry and in African-Americans (Ge et al., 2009). Moreover, the IL-28B rs12979860 C/T polymorphism appears to predict the rate of spontaneous clearance of $\mathrm{HCV}$, which could be observed in $53.0 \%$ of patients with the $\mathrm{C} / \mathrm{C}$ genotype $v s \mathrm{23.4 \%}$ of patients with the T/T genotype (Thomas et al., 2009).

The IL-28B gene encodes interferon-lamda 3 (IFN- $\lambda 3$ ), which belongs to the type III IFN family including IFN- $\lambda 1$, IFN- $\lambda 2$, and IFN- $\lambda 3$, and IFN- $\lambda$ interacts with a transmembrane receptor to induce potent antiviral responses, which are mediated through the activation of the JAKSTAT and MAPK pathways (Sheppard et al., 2003; Li et al., 2009). Therefore, allelic variants of the IL-28B polymorphism may be linked to the efficiency of the inflammatory process during $\mathrm{HCV}$ infection and to the mechanisms that $\mathrm{HCV}$ adopts to escape elimination by innate and adaptive immunity (Balagopal et al., 2010). If these studies are devoted to assess the role of the IL-28B rs $12979860 \mathrm{C} / \mathrm{T}$ polymorphism in patients with chronic HCV infection, it is possible that similar effects could also be expected in patients with chronic HBV infection, since type III IFN has been found to inhibit HBV and HCV replication in an experimental model (Robek et al., 2005).

During the last 3 years, a number of studies have assessed the association between the IL-28B rs12979860 C/T polymorphism and risk of HCC and liver cirrhosis (LC) development in different populations; however, the results are inconsistent and inconclusive (Barreiro et al., 2011; Ren et al., 2012). Different methodologies have been used, but in particular, most studies have used a small sample size, and it is therefore not surprising that there has been a lack of replication in the various studies. By using all the available published data to increase the statistical power, it is hypothesized that a meta-analysis could allow plausible candidate genes to be excluded and 
causative genes to be identified with reliability. We, therefore, conducted a meta-analysis in which all the published case-control studies were processed to confirm whether the IL-28B rs12979860 $\mathrm{C} / \mathrm{T}$ polymorphism increases the risk of HBV- or HCV-related HCC and LC development.

\section{MATERIAL AND METHODS}

\section{Literature search}

We searched PubMed, Elsevier, EMBASE, Web of Science, Wiley Online Library, and Chinese National Knowledge Infrastructure for all articles with the following search terms: ('IL28B' or 'interleukin 28B' or 'rs12979860') and ('hepatocellular carcinoma' or 'liver cancer' or 'liver cirrhosis' or 'cirrhosis'), where the last search update was August 1, 2012. Publication date and publication language were not restricted in our search. Reference lists were examined manually to further identify potentially relevant studies. We did not consider unpublished reports. If more than one article was published by the same author using the same case series, we selected the study where the most individuals were investigated.

\section{Inclusion and exclusion criteria}

We reviewed abstracts of all citations and retrieved studies. The following criteria were used to include published studies. 1) There were available genotype data for rs 12979860 with risk of HCC and/or LC using a case - control or cohort design. 2) HCC and LC cases were either histologically proven or diagnosed based on concordant clinical, biological, and morphological criteria. 3) Controls were composed of chronic hepatitis and free of cancer and LC. Studies were excluded if one of the following existed: 1) the design was based on family or sibling pairs; 2) the genotype frequency was not reported; or 3) there was insufficient information for extraction of data.

\section{Data extraction}

All data were extracted independently by 2 reviewers (G.J.S. and Z.X.Z.) according to the inclusion criteria listed above. Disagreements were resolved by discussion between the 2 reviewers. The following characteristics were collected from each study: first author, year of publication, country of sample, ethnicity, number of cases and controls, main background of cases and controls, matching criteria, and genotyping methods (Table 1).

\section{Statistical analysis}

The statistical analysis was conducted using STATA 11.0 (Stata Corp. LP, College Station, TX, USA); $\mathrm{P}<0.05$ was considered to be statistically significant. Hardy-Weinberg equilibrium in the controls was tested by the chi-square test for goodness of fit, and $\mathrm{P}<0.05$ indicated significant disequilibrium. Pooled odds ratios (ORs) were calculated for allele frequency comparison $(\mathrm{T} v s \mathrm{C})$, dominant model (TT+CT $v s \mathrm{CC})$, and recessive model (TT vs $\mathrm{CC}+\mathrm{CT}$ ). The significance of pooled ORs was determined by the Z-test and $\mathrm{P}<0.05$ was considered to be statistically significant. 
OR and $95 \%$ confidence intervals (CI) were estimated for each study in a randomeffect model or in a fixed-effect model. Heterogeneity among studies was examined with the $\chi^{2}$-based Q testing and $\mathrm{I}^{2}$ statistics (Higgins and Thompson, 2002). $\mathrm{P}<0.1$ was considered to be significant for the $\chi^{2}$-based $\mathrm{Q}$ testing and $\mathrm{I}^{2}$ was interpreted as the proportion of total variation contributed by between-study variation. If there was a significant heterogeneity $(\mathrm{P}<0.1)$, we selected a random-effect model (the DerSimonian and Laird method) to pool the data. If not, we selected a fixed-effect model (the Mantel-Haenszel method) to pool the data. Heterogeneity was also quantified using the $\mathrm{I}^{2}$ metric $\left(\mathrm{I}^{2}<25 \%\right.$, no heterogeneity; $\mathrm{I}^{2}=25-50 \%$, moderate heterogeneity; $\mathrm{I}^{2}>50 \%$, large or extreme heterogeneity) (Higgins and Thompson, 2002). Publication bias was examined with funnel plots and with Egger tests (Light and Pillemer, 1984; Egger et al., 1997). If there is evidence of publication bias, the funnel plot is noticeably asymmetric. For Egger tests, the significance level was set at 0.05 .

\section{RESULTS}

\section{Study characteristics}

A total of 50 papers were retrieved after the first search. After our selection, 7 casecontrol studies including $1152 \mathrm{HCC}$ and/or LC cases and 1326 controls fulfilled the inclusion criteria (Barreiro et al., 2011; Fabris et al., 2011; Falleti et al., 2011; Agundez et al., 2012; El-Awady et al., 2012; Eurich et al., 2012; Ren et al., 2012). The quality of the studies was considered acceptable for our meta-analysis. We calculated Hardy-Weinberg equilibrium for all 7 publications and found that only the study by Ren et al. (2012) was inconsistent with Hardy-Weinberg disequilibrium $(\mathrm{P}=0.0037)$. The flow chart of selection of studies and reasons for exclusion is presented in Figure 1. Studies had been carried out in Spain, Italy, Egypt, Germany, and China. Five studies focused on HCV-related liver diseases and 1 study on HBVrelated liver diseases, while 1 study focused on both. Characteristics of studies included in the meta-analysis are presented in Tables 1 and 2.

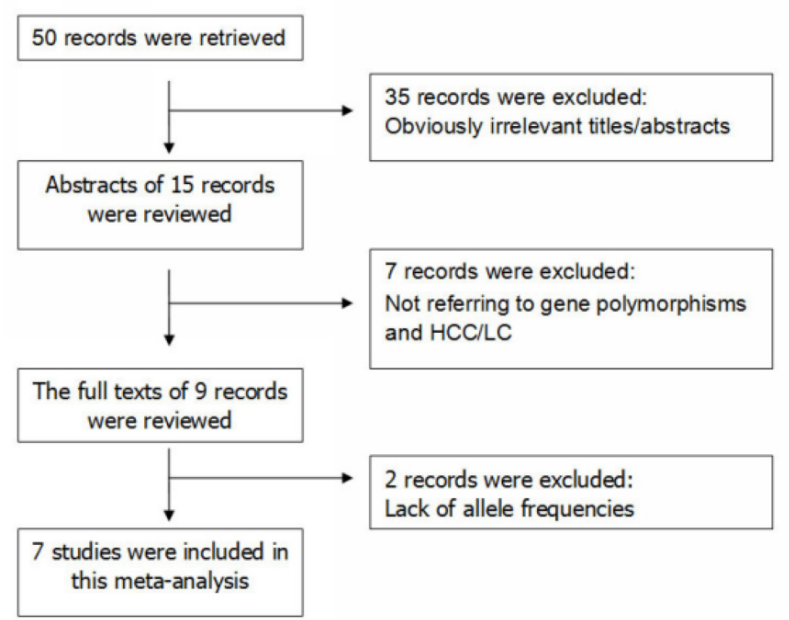

Figure 1. Flow chart of selection of studies and specific reasons for exclusion from the meta-analysis. 


\begin{tabular}{|c|c|c|c|c|c|c|c|c|}
\hline Author & Year & Country & Ethnicity & $\begin{array}{l}\text { No. (cases } \\
\text { /controls) }\end{array}$ & $\begin{array}{l}\text { Case main } \\
\text { background }\end{array}$ & $\begin{array}{l}\text { Control main } \\
\text { background }\end{array}$ & $\begin{array}{l}\text { Matching } \\
\text { criteria }\end{array}$ & $\begin{array}{l}\text { Genotyping } \\
\text { methods }\end{array}$ \\
\hline Barreiro & 2011 & Spain & Caucasian & $56 / 248$ & HCV-induced LC & $\mathrm{CHC}$ & $\begin{array}{l}\text { Age, gender, } \\
\text { race }\end{array}$ & PCR-sequencing \\
\hline Fabris $(a) *$ & 2011 & Italy & Caucasian & $75 / 57$ & HBV-induced LC & $\mathrm{CHB}$ & Race & PCR-RFLP \\
\hline Fabris (b)* & 2011 & Italy & Caucasian & $199 / 235$ & $\mathrm{HCV}$-induced LC & $\mathrm{CHC}$ & Race & PCR-RFLP \\
\hline Falleti & 2011 & Italy & Caucasian & $328 / 301$ & HCV-induced LC & $\mathrm{CHC}$ & Race & PCR-RFLP \\
\hline Fabris $(\mathrm{c})^{*}$ & 2011 & Italy & Caucasian & $35 / 85$ & $\mathrm{HCV}$-induced $\mathrm{HCC}$ & $\mathrm{CHC}$ & Race & PCR-RFLP \\
\hline Agundez & 2012 & Spain & Caucasian & $134 / 98$ & $\mathrm{HCV}$-induced HCC & $\mathrm{CHC}$ & Race & TaqMan \\
\hline El-Awady & 2012 & Egypt & Caucasian & $110 / 110$ & $\mathrm{HCV}$-induced HCC & $\mathrm{CHC}$ & Race & PCR-RFLP \\
\hline Eurich & 2012 & Germany & Caucasian & $61 / 106$ & $\mathrm{HCV}$-induced HCC & $\mathrm{CHC}$ & $\begin{array}{l}\text { Age, gender, } \\
\text { race }\end{array}$ & TaqMan \\
\hline Ren & 2012 & China & Asian & $154 / 86$ & HBV-induced HCC & $\mathrm{CHB}$ & Race & TaqMan \\
\hline
\end{tabular}

*Fabris's study included 3 groups of samples with different types of liver disease and infected hepatitis virus. As the 3 groups were independent of each other and analyzed separately, data were extracted according to the groups $(\mathrm{a}, \mathrm{b}$, and $\mathrm{c})$ in the initial study. $\mathrm{LC}=$ liver cirrhosis; $\mathrm{HCC}=$ hepatocellular carcinoma; $\mathrm{CHB}=$ chronic hepatitis $\mathrm{B}$; $\mathrm{CHC}=$ chronic hepatitis $\mathrm{C}$; PCR-RFLP $=$ polymerase chain reaction-restriction fragment length polymorphism.

Table 2. Genotype frequencies of rs12979860 in studies included in the meta-analysis.

\begin{tabular}{|c|c|c|c|c|c|c|c|c|}
\hline \multirow[t]{2}{*}{ Author } & \multirow[t]{2}{*}{ Year } & \multicolumn{3}{|c|}{ Case genotype* } & \multicolumn{3}{|c|}{ Control genotype** } & \multirow[t]{2}{*}{ HWE } \\
\hline & & $\mathrm{CC}$ & $\mathrm{CT}$ & TT & $\mathrm{CC}$ & $\mathrm{CT}$ & TT & \\
\hline Barreiro & 2011 & 34 & 16 & 6 & 105 & 115 & 28 & 0.4482 \\
\hline Fabris (a) & 2011 & 63 & 102 & 34 & 70 & 143 & 22 & 0.7332 \\
\hline Fabris (b) & 2011 & 36 & 35 & 4 & 31 & 20 & 6 & 0.2725 \\
\hline Falleti & 2011 & 109 & 162 & 57 & 96 & 170 & 35 & 0.7304 \\
\hline Fabris (c) & 2011 & 6 & 21 & 8 & 23 & 50 & 12 & 0.8259 \\
\hline Agundez & 2012 & 52 & 66 & 16 & 37 & 49 & 11 & 0.595 \\
\hline El-Awady & 2012 & 0 & 88 & 30 & 14 & 83 & 13 & 0.7877 \\
\hline Eurich & 2012 & 13 & 31 & 17 & 35 & 57 & 14 & 0.8087 \\
\hline Ren & 2012 & 115 & 29 & 10 & 62 & 17 & 6 & 0.0037 \\
\hline
\end{tabular}

*Absolute number of patients; **Absolute number of controls; HWE = Hardy-Weinberg equilibrium; it was evaluated using the goodness-of-fit chi-square test. $\mathrm{P}<0.05$ was considered representative of a departure from HWE.

\section{Evaluation of the IL-28B rs12979860 polymorphism and association with HCC and LC}

There were 5 case-control studies (Fabris et al., 2011; Agundez et al., 2012; El-Awady et al., 2012; Eurich et al., 2012; Ren et al., 2012), which had been performed to study the rs 12979860 polymorphism and HCC risk. The results of the meta-analysis are shown in Table 3 . The results showed that there was significant association between the rs 12979860 polymorphism and $\mathrm{HCC}$ risk $(\mathrm{TT}$ vs $\mathrm{CC}+\mathrm{CT}$, pooled $\mathrm{OR}=1.757,95 \% \mathrm{CI}=1.204-2.562, \mathrm{P}=0.003$; $\mathrm{TT}+\mathrm{CT}$ vs $\mathrm{CC}$, pooled $\mathrm{OR}=1.387,95 \% \mathrm{CI}=1.012-1.901, \mathrm{P}=0.042)$; when only HCV-related HCC studies were included, the results showed that pooled OR became larger and the association was still significant under the recessive model (TT $v s \mathrm{CC}+\mathrm{CT}$, pooled $\mathrm{OR}=1.935,95 \% \mathrm{CI}$ $=1.292-2.900, \mathrm{P}=0.001)$.

There were 3 case-control studies (Barreiro et al., 2011; Fabris et al., 2011; Falleti et al., 2011), which had been performed to study the rs 12979860 polymorphism and LC risk. The results of the meta-analysis are shown in Table 3. The results showed that there was a significant 
association between the rs12979860 polymorphism and LC risk (TT vs $\mathrm{CC}+\mathrm{CT}$, pooled $\mathrm{OR}=$ $1.492,95 \% \mathrm{CI}=1.087-2.049, \mathrm{P}=0.013)$; when only HCV-related LC studies were included, the results showed that pooled OR became larger and the association was still significant under the recessive model (TT vs $\mathrm{CC}+\mathrm{CT}$, pooled $\mathrm{OR}=1.609,95 \% \mathrm{CI}=1.159-2.235, \mathrm{P}=0.005)$.

\begin{tabular}{|c|c|c|c|c|c|c|}
\hline Genetic model & Disease model & Pooled OR (95\%CI) & P value* & $\begin{array}{c}\text { P value** } \\
\text { (publication bias) }\end{array}$ & $\begin{array}{c}\text { P value*** } \\
\text { (heterogeneity) }\end{array}$ & $\mathrm{I}^{2}$ \\
\hline \multirow[t]{3}{*}{$\mathrm{T} v s \mathrm{C}$} & $\mathrm{HCC}$ & $1.189(0.956-1.478)$ & 0.12 & 0.748 & 0.696 & $0 \%$ \\
\hline & $\mathrm{LC}$ & $1.007(0.845-1.200)$ & 0.941 & 0.435 & 0.509 & $0 \%$ \\
\hline & $\mathrm{HCC}$ and $\mathrm{LC}$ & $1.075(0.938-1.232)$ & 0.301 & 0.921 & 0.664 & $0 \%$ \\
\hline \multicolumn{7}{|l|}{ Dominant } \\
\hline \multirow[t]{3}{*}{$\mathrm{TT}+\mathrm{CT}$ vs $\mathrm{CC}$} & $\mathrm{HCC}$ & $1.387(1.012-1.901)^{*}$ & 0.042 & 0.018 & 0.053 & $57.20 \%$ \\
\hline & $\mathrm{LC}$ & 0.874 (0.699-1.092) & 0.235 & 0.791 & 0.137 & $45.80 \%$ \\
\hline & $\mathrm{HCC}$ and $\mathrm{LC}$ & $1.021(0.852-1.224)$ & 0.818 & 0.064 & 0.029 & $53.40 \%$ \\
\hline \multicolumn{7}{|l|}{ Recessive } \\
\hline \multirow{6}{*}{$\mathrm{TT}$ vs $\mathrm{CC}+\mathrm{CT}$} & $\mathrm{HCC}$ & $1.757(1.204-2.562)^{*}$ & 0.003 & 0.260 & 0.305 & $17.20 \%$ \\
\hline & $\mathrm{LC}$ & $1.492(1.087-2.049)^{*}$ & 0.013 & 0.124 & 0.182 & $38.40 \%$ \\
\hline & $\mathrm{HCC}$ and $\mathrm{LC}$ & $1.597(1.254-2.036)^{*}$ & $<0.0001$ & 0.147 & 0.259 & $20.70 \%$ \\
\hline & HCV-related HCC & $1.935(1.292-2.900)^{*}$ & 0.001 & 0.624 & 0.373 & $4 \%$ \\
\hline & HCV- related LC & $1.609(1.159-2.235)^{*}$ & 0.005 & 0.522 & 0.407 & $0 \%$ \\
\hline & HCV-related HCC and LC & $1.732(1.343-2.235)^{*}$ & $<0.0001$ & 0.742 & 0.495 & $0 \%$ \\
\hline
\end{tabular}

*The random-effect model was used when $\mathrm{P}<0.10$ for the heterogeneity test, otherwise the fixed-effect model was used. **The Egger test was used to evaluate publication bias and $\mathrm{P}<0.05$ was considered to be statistically significant. ${ }^{* * *} \mathrm{P}<0.1$ was considered to be statistically significant for $\mathrm{Q}$ statistics. "Significant pooled odds ratios (ORs) and $95 \%$ confidence intervals (CI).

When studies for HCC and LC risks were combined, the results for all studies showed that there was a significant association between the rs12979860 polymorphism and risk of the two diseases (TT vs $\mathrm{CC}+\mathrm{CT}$, pooled $\mathrm{OR}=1.597,95 \% \mathrm{CI}=1.254-2.036, \mathrm{P}<0.0001$ ) (Figure 2A); when only HCV-related HCC and LC studies were included, the results showed that pooled OR also became larger and the association was still significant under the recessive model (TT vs $\mathrm{CC}+\mathrm{CT}$, pooled $\mathrm{OR}=1.732,95 \% \mathrm{CI}=1.343-2.235, \mathrm{P}<0.0001$ ) (Figure 2B). The results of the meta-analysis are shown in Table 3.
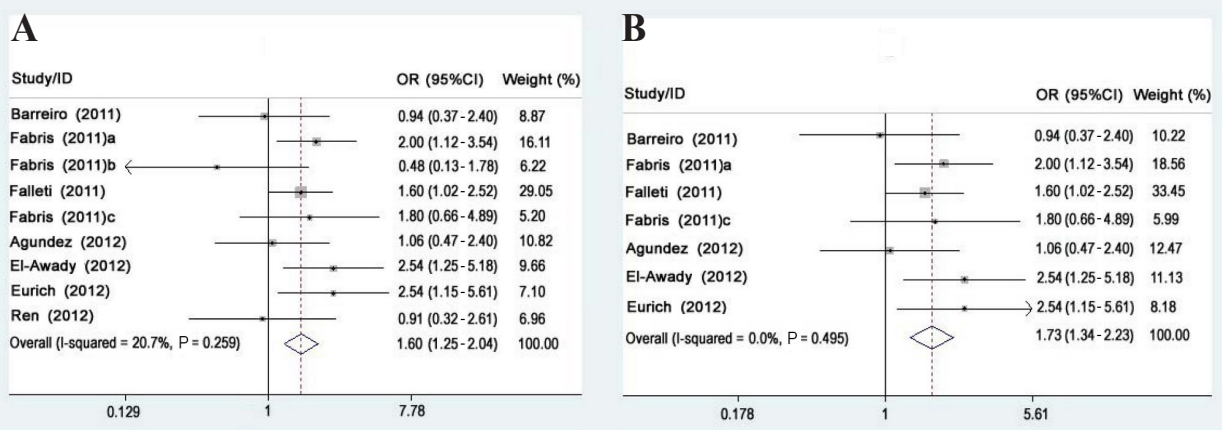

Figure 2. Forest plots of all studies and hepatitis $\mathrm{C}$ virus (HCV)-related studies in the comparison between rs12979860 genotype TT and CT+CC. A. All studies are included. B. Only HCV-related studies are included. The squares and horizontal lines correspond to the study-specific OR and $95 \% \mathrm{CI}$. The area of the squares reflects the study-specific weight. The diamond represents the pooled OR and $95 \%$ CI. 


\section{Sensitivity analysis}

The influence of a single study on the overall meta-analysis estimate was investigated by omitting one study at a time, and the omission of any study made no significant difference, indicating that our results were statistically reliable.

\section{Evaluation of heterogeneity and publication bias}

Under genetic model of $\mathrm{T} v \mathrm{C}$, no statistically significant heterogeneity was observed in either the HCC or LC study, or for the combined study ( $\mathrm{P}>0.1$ in all 3 by the $\chi^{2}$-based Q testing and $\left.\mathrm{I}^{2}=0\right)$. Under the dominant model $(\mathrm{TT}+\mathrm{CT} v s \mathrm{CC})$, reversely, the heterogeneity in all 3 disease models existed. Conversely for HCC and the combined study, large heterogeneity was detected $\left(\mathrm{P}=0.053, \mathrm{I}^{2}=57.20 \%\right.$ for the HCC study and $\mathrm{P}=0.029, \mathrm{I}^{2}=53.40 \%$ for the combined study). For the LC study, moderate heterogeneity was detected $\left(\mathrm{P}=0.137, \mathrm{I}^{2}=45.80 \%\right)$. Under the recessive model (TT vs $\mathrm{CC}+\mathrm{CT})$, moderate heterogeneity was detected in the LC study $(\mathrm{P}=$ $0.182, \mathrm{I}^{2}=38.40 \%$ ). However, when only HCV-related LC studies were included, statistically significant heterogeneity was no longer observed $\left(\mathrm{P}=0.407, \mathrm{I}^{2}=0\right)$. Funnel plots and the Egger test were used to assess the publication bias of the literature. Only 1 publication bias was observed in the HCC study ( $\mathrm{P}=0.018$ for the Egger test), under the dominant model (TT+CT vs $\mathrm{CC}$ ). No publication bias was observed in other models $(\mathrm{P}>0.05$ for the Egger test) and symmetric funnel plots were obtained. Results of heterogeneity and publication bias are shown in Table 2 .

\section{DISCUSSION}

Since 2009, several independent genome-wide association studies have reported an association between genetic polymorphisms within the IL-28B promoter and both natural and treatment-induced clearance in genotype $1 \mathrm{HCV}$-infected patients (Tanaka et al., 2009; Rauch et al., 2010). Meanwhile, different studies have shown a strong association and importance of the IL-28B rs12979860 T/C polymorphism in the treatment response and spontaneous clearance of HCV. The carriers of the favorable genotypes have a higher rate of spontaneous clearance of $\mathrm{HCV}$ during the acute phase of the infection. Meanwhile, $80 \%$ of patients who carry 2 copies of this advantageous variant clear the virus during IFN therapy and remain virus-free with a sustained viral response. This mutation is more common in Caucasian and Asian populations, whereas it is only found in $40-50 \%$ of sub-Saharan Africans who are known to be more resistant to combination therapy (Thomas et al., 2009; Montes-Cano et al., 2010; Tillmann et al., 2010).

Besides, several global studies have revealed that the $\mathrm{C} / \mathrm{C}$ genotype is the major player in drug-induced viral clearance, while both the $\mathrm{C} / \mathrm{T}$ and $\mathrm{T} / \mathrm{T}$ genotypes have a poor association with clearance rates (Liao et al., 2011; Ruiz-Extremera et al., 2011). Similarly, host factors control tolerance to chronic HBV infection and can fluctuate over time with increased risk of progression to cirrhosis and particularly HCC (Eksteen, 2011). As HCC and LC represent the most advanced step in the natural course of chronic hepatitis infection, if the hypothesis of the existence of any relationship between the IL-28B genetic polymorphism and the severity of HBV- or HCV-induced liver disease holds true, the most logical finding should be the existence of differences in genotype frequencies between the different stages of the disease. 
The data from this meta-analysis showed a significant difference in genotype frequency of T/T for the IL-28B rs12979860 C/T polymorphism between patients with hepatitis virus-related HCC and/or LC and those with chronic hepatitis. The differences clearly suggested that genotype T/T of rs 12979860 was a genetic contributor for the development of HCC and LC after hepatitis virus infection, especially for the history of HCV infection. Our results support previous findings reporting that the carrier state of the minor alleles at rs 12979860 site is associated with more severe liver fibrosis $(\mathrm{P}<0.001)$ in a group of 131 patients with thalassemia major and chronic HCV infection who underwent a liver biopsy (Di et al., 2012). It is also reported that the rate of spontaneous clearance of $\mathrm{HCV}$ infections is significantly different between patients with a $\mathrm{C} / \mathrm{C}$ genotype and those with a T/T genotype (53.0 vs 23.4\%) (Thomas et al., 2009). Such results indicate that the presence of the T/T genotype may be associated with HCV persistence. Since the IL-28B gene encodes IFN- $\lambda 3$, which participates in antiviral responses and the inflammatory process (Balagopal et al., 2010), and since allelic variants of the IL-28B polymorphism may affect the efficiency of the inflammatory process, chronic hepatitis patients with the T/T genotype of IL-28B polymorphism may suffer more injury to liver cells, which could lead to cirrhosis or HCC. Moreover, IFN- $\lambda 3$ has been found to possess antitumor activity in a BNL hepatoma model (Abushahba et al., 2010), and the relationship between such antitumor activity and HCC occurrence and whether the T/T genotype of IL28B polymorphism is linked with antitumor activity are worthy of further study.

The degree of heterogeneity is one of the major concerns in a sound meta-analysis because non-homogeneous data are liable to result in misleading results. In the present study, Q testing and $\mathrm{I}^{2}$ statistics were carried out to determine the significance of heterogeneity. Under the dominant model (TT+CT vs CC), there was heterogeneity in all 3 disease models. Also, the study by El-Awady et al. (2012) was found to be responsible for the heterogeneity. After removing this study, no significant heterogeneity was observed $(\mathrm{P}>0.1$ for $\mathrm{Q}$ testing; data not shown). A moderate heterogeneity was detected in the LC study under the recessive model (TT vs CC+CT); after removing HBV-related LC studies, no heterogeneity was observed $(\mathrm{P}=$ $0.407, \mathrm{I}^{2}=0$ ). No statistically significant heterogeneity was observed under the other models. Moreover, we performed a sensitivity analysis by removing one study each time and rerunning the model to determine the effect on each overall estimate. The estimates changed little, which implied that our results were statistically reliable.

However, there were still some limitations in this meta-analysis. 1) In 7 studies included for our analysis, only 2 of them focused on HBV-related liver diseases, so lack of HBVrelated studies may be a limitation for explaining our results. Similarly, only 1 study involved Asian samples, and our results may not be representative for the Asian population. 2) Because the samples from 5 countries and controls were not uniform, as in most meta-analyses, results should be interpreted with caution. 3) The number of studies and the number of subjects in the studies included in the meta-analysis were small, and thus, caution should be adopted when explaining our results. 4) Meta-analysis is a retrospective research that is subject to methodological limitations. To minimize the bias, we used explicit methods for study selection, data extraction and data analysis. Nevertheless, our results should be interpreted with caution.

This meta-analysis suggests that the IL-28B rs12979860 C/T polymorphism is associated with hepatitis virus-related HCC and LC. The pooled ORs in this study suggest that the rs12979860/TT homozygote has a modest but definite genetic effect. Larger and welldesigned studies based on different ethnic groups are needed to confirm our results. 


\section{REFERENCES}

Abushahba W, Balan M, Castaneda I, Yuan Y, et al. (2010). Antitumor activity of type I and type III interferons in BNL hepatoma model. Cancer Immunol. Immunother. 59: 1059-1071.

Agundez JA, Garcia-Martin E, Maestro ML, Cuenca F, et al. (2012). Relation of IL28B gene polymorphism with biochemical and histological features in hepatitis $\mathrm{C}$ virus-induced liver disease. PloS One 7: e37998.

Balagopal A, Thomas DL and Thio CL (2010). IL28B and the control of hepatitis C virus infection. Gastroenterology 139: 1865-1876.

Barreiro P, Pineda JA, Rallon N, Naggie S, et al. (2011). Influence of interleukin-28B single-nucleotide polymorphisms on progression to liver cirrhosis in human immunodeficiency virus-hepatitis $\mathrm{C}$ virus-coinfected patients receiving antiretroviral therapy. J. Infect. Dis. 203: 1629-1636.

Bowen DG and Walker CM (2005). Adaptive immune responses in acute and chronic hepatitis C virus infection. Nature 436: 946-952.

Bruno S and Facciotto C (2008). The natural course of HCV infection and the need for treatment. Ann. Hepatol. 7: 114-119.

Di M, V, Bronte F, Calvaruso V, Capra M, et al. (2012). IL28B polymorphisms influence stage of fibrosis and spontaneous or interferon-induced viral clearance in thalassemia patients with hepatitis C virus infection. Haematologica 97: 679-686.

Egger M, Davey SG, Schneider M and Minder C (1997). Bias in meta-analysis detected by a simple, graphical test. $B M J$ 315: 629-634.

Eksteen B (2011). Infections and the liver. Dig. Dis. 29: 184-190.

El-Awady MK, Mostafa L, Tabll AA, Abdelhafez TH, et al. (2012). Association of IL28B SNP With Progression of Egyptian HCV Genotype 4 Patients to End Stage Liver Disease. Hepat. Mon. 12: 271-277.

Eurich D, Boas-Knoop S, Bahra M, Neuhaus R, et al. (2012). Role of IL28B polymorphism in the development of hepatitis C virus-induced hepatocellular carcinoma, graft fibrosis, and posttransplant antiviral therapy. Transplantation 93: 644-649.

Fabris C, Falleti E, Cussigh A, Bitetto D, et al. (2011). IL-28B rs12979860 C/T allele distribution in patients with liver cirrhosis: role in the course of chronic viral hepatitis and the development of HCC. J. Hepatol. 54: 716-722.

Falleti E, Bitetto D, Fabris C, Cussigh A, et al. (2011). Role of interleukin 28B rs12979860 C/T polymorphism on the histological outcome of chronic hepatitis C: relationship with gender and viral genotype. J. Clin. Immunol. 31: 891-899.

Fattovich G, Giustina G, Schalm SW, Hadziyannis S, et al. (1995). Occurrence of hepatocellular carcinoma and decompensation in western European patients with cirrhosis type B. The EUROHEP Study Group on Hepatitis B Virus and Cirrhosis. Hepatology 21: 77-82.

Ge D, Fellay J, Thompson AJ, Simon JS, et al. (2009). Genetic variation in IL28B predicts hepatitis C treatment-induced viral clearance. Nature 461: 399-401.

Higgins JP and Thompson SG (2002). Quantifying heterogeneity in a meta-analysis. Stat. Med. 21: 1539-1558.

Ikeda K, Saitoh S, Suzuki Y, Kobayashi M, et al. (1998). Disease progression and hepatocellular carcinogenesis in patients with chronic viral hepatitis: a prospective observation of 2215 patients. J. Hepatol. 28: 930-938.

Lavanchy D (2004). Hepatitis B virus epidemiology, disease burden, treatment, and current and emerging prevention and control measures. J. Viral. Hepat. 11: 97-107.

Leone N and Rizzetto M (2005). Natural history of hepatitis C virus infection: from chronic hepatitis to cirrhosis, to hepatocellular carcinoma. Minerva Gastroenterol. Dietol. 51: 31-46.

Li M, Liu X, Zhou Y and Su SB (2009). Interferon-lambdas: the modulators of antivirus, antitumor, and immune responses. J. Leukoc. Biol. 86: 23-32.

Liao XW, Ling Y, Li XH, Han Y, et al. (2011). Association of genetic variation in IL28B with hepatitis C treatmentinduced viral clearance in the Chinese Han population. Antivir. Ther. 16: 141-147.

Light RJ and Pillemer DB (1984). Summing Up: The Science of Reviewing Research. Harvard University Press, Cambridge.

Montes-Cano MA, Garcia-Lozano JR, Abad-Molina C, Romero-Gomez M, et al. (2010). Interleukin-28B genetic variants and hepatitis virus infection by different viral genotypes. Hepatology 52: 33-37.

Morgan TR (2011). Chemoprevention of hepatocellular carcinoma in chronic hepatitis C. Recent Results Cancer Res. 188: 85-99.

Nash KL, Woodall T, Brown AS, Davies SE, et al. (2010). Hepatocellular carcinoma in patients with chronic hepatitis C virus infection without cirrhosis. World J. Gastroenterol. 16: 4061-4065.

Poynard T, Bedossa P and Opolon P (1997). Natural history of liver fibrosis progression in patients with chronic hepatitis C. The OBSVIRC, METAVIR, CLINIVIR, and DOSVIRC groups. Lancet 349: 825-832.

Rauch A, Kutalik Z, Descombes P, Cai T, et al. (2010). Genetic variation in IL28B is associated with chronic hepatitis C and treatment failure: a genome-wide association study. Gastroenterology 138: 1338-1345. 
Ren S, Lu J, Du X, Huang Y, et al. (2012). Genetic variation in IL28B is associated with the development of hepatitis B-related hepatocellular carcinoma. Cancer Immunol. Immunother. 61: 1433-1439.

Robek MD, Boyd BS and Chisari FV (2005). Lambda interferon inhibits hepatitis B and C virus replication. J. Virol. 79: 3851-3854.

Ruiz-Extremera A, Munoz-Gamez JA, Salmeron-Ruiz MA, de Rueda PM, et al. (2011). Genetic variation in interleukin 28B with respect to vertical transmission of hepatitis $\mathrm{C}$ virus and spontaneous clearance in HCV-infected children. Hepatology 53: 1830-1838.

Sheppard P, Kindsvogel W, Xu W, Henderson K, et al. (2003). IL-28, IL-29 and their class II cytokine receptor IL-28R. Nat. Immunol. 4: 63-68.

Tanaka Y, Nishida N, Sugiyama M, Kurosaki M, et al. (2009). Genome-wide association of IL28B with response to pegylated interferon-alpha and ribavirin therapy for chronic hepatitis C. Nat. Genet. 41: 1105-1109.

Thomas DL, Thio CL, Martin MP, Qi Y, et al. (2009). Genetic variation in IL28B and spontaneous clearance of hepatitis C virus. Nature 461: 798-801.

Tillmann HL, Thompson AJ, Patel K, Wiese M, et al. (2010). A polymorphism near IL28B is associated with spontaneous clearance of acute hepatitis C virus and jaundice. Gastroenterology 139: 1586-92, 1592.

Villeneuve JP (2005). The natural history of chronic hepatitis B virus infection. J. Clin. Virol. 34 (Suppl 1): S139-S142. 